\title{
Coupled reliability model of biodeterioration, chloride ingress and cracking for reinforced concrete structures
}

\author{
Emilio Bastidas-Arteaga ${ }^{a}$, Mauricio Sánchez-Silva ${ }^{a}$ \\ Alaa Chateauneuf ${ }^{b}$, Moema Ribas Silva ${ }^{c}$ \\ ${ }^{a}$ Department of Civil and Environmental Engineering. Universidad de los Andes, \\ Carrera 1 N. 18A-70 EdificioW, Piso 3. Bogotá, Colombia \\ ${ }^{b}$ LGC-UBP\&CUST, Clermond-Ferrand, Campus des Cézeaux - BP 20663174 Aubière cedex, France \\ ${ }^{c}$ Universidade Federal do Espírito Santo, Vitoria, Brazil
}

\begin{abstract}
Maintaining and operating civil infrastructure systems has been recognized as a critical issue worldwide. Among all possible causes of safety reduction during the structural lifetime, deterioration is particularly important. Structural deterioration is usually a slow time-dependent process controlled by safety and operation threshold specifications. This paper presents a model of RC deterioration by coupling biodeterioration (i.e., chemical, physical and mechanical action of live organisms), steel corrosion, and concrete cracking. The final purpose of the model is to compute the reduction of the concrete section and the area of steel reinforcement in order to assess the change of structural capacity with time. Given the uncertainties in both the parameters and the model, the probabilistic nature of loads, the material properties and the difussion process are taken into account to evaluate structural reliability. The model is illustrated with an example where the inelastic behavior of a pile subject to random loading is considered. The results of the analysis have shown that the effect of biodeterioration on the structural performance is significant and can cause an important reduction of its lifetime. On the whole, The paper states that modeling the effects of biodeterioration in RC structures should be included as part of infrastructure planning and design, especially, when they are located in aggressive environments.
\end{abstract}

Keywords: Biodeterioration, chloride ingress, corrosion, crack initiation, crack propagation, reliability.

\section{Introduction}

Civil infrastructure systems are critical assets for any country's socioeconomic development. Designing these systems for a particular service lifetime and maintaining them in operation has been recognized as a critical issue worldwide. The life-cycle of a structure can be thought of as the time during which the structure is able to meet specific technical requirements with an acceptable level of safety. In lifecycle analysis, the technical problem focuses on defining the interaction among three main processes: (1) the structural deterioration (e.g., aging, obsolescence), (2) the occurrence of unexpected extreme events (e.g., earthquakes, floods); and (3) the maintenance/rehabilitation program (Santander and Sánchez-Silva, 2006 [1]). This paper will focus only on the first aspect. Nowadays, many deteriorated structures are evaluated for possible repair and continued service because they are in a situation where their replacement would be economically unfeasible. Thus, developing robust models for prediction and strategies for periodic inspection and maintenance play a significant role in enabling target reliabilities to be met over a period of continued service (Mori and Ellingwood, 1995 [6], Clifton, 1993 [7]).

Deterioration is common in structures located in aggressive environments and subjected to, for instance, sulfate attack or chloride penetration causing corrosion and biodeterioration. Numerous studies 
have addressed the problem of chloride ingress in concrete structures. However, in addition to chloride penetration, biological processes can accelerate the degradation process by modifying severely the structural durability and reliability. This aspect is particularly important in marine structures (e.g., ports and offshore platforms), sewage systems and waste water treatment plants (Piedrahita, 2004 [2]; Cho and Mori, 1995[3]; Morton et al., 1991[4]).

The cause of failure of reinforced concrete $(\mathrm{RC})$ structures subject to deterioration is a loss of capacity resulting from a combination of steel corrosion and concrete cracking. Corrosion leads to a loss of the effective area of the reinforcement and has proven to be a common cause of failure. In a study conducted by CC Technologies Laboratories Inc. in 2001 [5], it was found that the total direct cost of corrosion in USA is close to US\$137.9 billion/year. The industrial and infrastructure sectors more susceptible to corrosion damage are shown in Table 1. On the other hand, concrete cracking is the result of many factors among which loading, steel corrosion and the action of live organisms are of particular interest.

Structural deterioration is usually a slow time-dependent process controlled by a safety/operation threshold specification. In RC structures, cover reduction is caused by the joint action of live organisms and the accumulation of large amounts of chlorides and carbon dioxide on the structure surface. As concrete cover is the principal mean of protection from corrosion, live organisms facilitate the diffusion process by eroding the concrete surface and destroying the concrete microstructure. This accelerates the initiation of steel corrosion and increases the corrosion rate. Predicting the deterioration of RC structures due to chloride penetration when accelerated by live organisms depends on many factors. It is first necessary that the chloride and carbon dioxide concentration on the structural surface become high enough. Besides, it is required that the environment provides conditions for live organisms to survive and to carry out their vital processes, i.e., appropriate climate conditions, temperature, light intensity, oxygen availability, surface roughness and so forth. Biodeterioration of concrete structures is a subject that requires further analytical and experimental investigation.

This paper presents a work on modeling RC deterioration by coupling biodeterioration (i.e., action of live organisms), steel corrosion, and concrete cracking. The final purpose of the model is to compute the reduction of the concrete section and the area of steel reinforcement in order to assess the change of structural capacity with time. Given the uncertainties in both the parameters and the model, the probabilistic nature of loads, the material properties and the difussion process are taken into account to evaluate structural reliability. The RC deterioration is discussed in section 2 , reinforcement corrosion induced by chloride ingress is treated in section 3 and the proposed model is presented in section 4 . Finally, as an illustrative example, the model has been applied to evaluate the inelastic performance of $\mathrm{RC}$ piles located in aggressive environments.

\section{Reinforced concrete deterioration}

\subsection{Cracking and corrosion}

In optimal conditions, the durability of RC structures is high and the variation of the structural reliability with time is not significant. However, for special structures located in aggressive environments this might not be the case. Some examples of aggressive environments are those in which there is:

1. high relative humidity (i.e., between $60 \%$ and $98 \%$ );

2. cycles of humidification and drying, of freezing and defrosting;

3. high carbon dioxide concentrations (e.g., carbonation in urban atmospheres);

4. high concentration of chlorides or other salts (e.g., marine environments); or

5. high concentration of sulfates and small amounts of acids (e.g., sewer pipes or residual water treatment plants). 
In any deterioration process, the structural reliability becomes a time-dependent process; for the particular case of chloride penetration leading to steel corrosion in RC structures, this process has been widely studied. The time-dependent reliability problem is described schematically in Figure 1. The structure life-cycle can be divided into three stages (Mori and Ellingwood, 1993 [8]; and ThoftChristensen, $2002[9])$ :

- Stage 1: after construction structural reliability is maximum; then, deterioration initiates as a result of the environmental conditions such as: chloride ingress, carbonation, sulfate attack, biodeterioration, erosion, etc. Nevertheless, the consequences of these actions do not have a significant impact in the reliability until their individual or joint actions create the necessary conditions to depassivate the protective layer of the steel, e.g., low $p H$ of concrete, optimal temperature, water and oxygen. As a result of this new state, the reinforcement starts to be corroded actively; this time is called time of corrosion initiation $\left(\tau_{i n i}\right)$ (see also Figure $2 \mathrm{a}$ ).

- Stage 2: as soon as corrosion starts, corrosion products appear. Since these products have a lower density, they occupy the porous zone of concrete around the steel. When the total amount of corrosion products exceeds the amount needed to fill the porous zone, an expansive pressure is induced on the concrete initiating the cracking process (Liu, 1996 [10]; and Liu and Weyers, 1998 [11]). In this stage, two phenomena called crack initiation and crack propagation are present. The former is defined as the condition for which a hairline crack of $0.05 \mathrm{~mm}$ width appears $(\mathrm{Vu}$ and Stewart, 2005 [12] and Vu et al., 2005 [13]). The time required to reach this point is called time to crack initiation $\left(\tau_{c r}\right)$ (Figure $2 \mathrm{~b}$ ). The last is measured in terms of the crack width, $c w$. The time required to reach the threshold crack size, $c w_{\text {lim }}$ (e.g., $c w_{\text {lim }}=0.5 \mathrm{~mm}$ ) is called time to severe cracking, $\left(\tau_{s p}\right)$. Once this stage starts, the reliability decay can play an important role in the structural safety.

- Stage 3: when crack width reaches the threshold value, there is a significant increment of the corrosion rate as a result of an increase in water and oxygen availability and in concrete electrical conductivity (i.e. Schiessl and Raupach, 1997 [14]). This increment induces a reliability decay of an appreciable magnitude.

\subsection{Biodeterioration}

The process of deterioration of RC structures as a result of the action of live organisms (chemical and physical) is usually called concrete biodeterioration. Biodeterioration was defined by Hueck, 1965 [15] as: "...any undesirable change produced by normal activities of live organisms on materials". According to Gaylarde, 2003 [16], biodeterioration can be classified within three types:

- Aesthetic: it is concerned with the presence of microorganisms on the surface of the structure producing a disagreeable aspect.

- Chemical: it refers to the degradation of cement and aggregates as a result of substances emanated by live organisms.

- Physical: encompasses all physical actions of organisms leading to a physical deterioration of RC.

Biodeterioration is caused by live organisms that can be found in the ground, the water or the air. In many cases, they can be found on concrete surfaces that offer favorable conditions for them to survive; for example, places where the surface texture allows them to settle down, there is water available, the $p H$ of concrete is low, the temperature conditions are appropriate and where there are nutrients for their survival. When these organisms settle on the concrete surface, they form a film called biofilm, from where they start to deteriorate the concrete.

Biodeterioration is caused mainly by: (1) bacteria; (2) fungi; (3) algae and lichens; and (4) organisms that erode and drill the concrete (Gaylarde et al., 2003 [17]). 


\subsubsection{Bacteria}

They are unicellular microorganisms with the size of one micron or less. They can be classified as autotrophic or heterotrophic; also, they can be aerobe, anaerobe or aerotolerant anaerobes (see Appendix A for definitions). Among those that cause concrete deterioration some of the most important are: (1) cyanobacteria; (2) nitrobacteria; (3) sulfur-reducing bacteria; and (4) sulfur-oxidizing bacteria. Their main characteristics are presented in Table 2.

The chemical action of cyanobacterias does not affect RC considerably, however, its organic material secretion serves as nutrient for fungi and heterotrophic bacteria that can be very aggressive to RC. Regarding the physical degradation, the endolithic cells penetrate in concrete through micro-cracks absorbing water, which causes a growth of their molecular mass generating tensile stresses leading to an increment in the size of cracks (Gaylarde, 2003 [16]).

Nitrobacteria transform ammonia from the atmosphere into nitrites and nitrates; this process is called nitrification. Nitrites and nitrates attack the concrete and as a result of the reaction, "calcium nitrate" is produced. It affects the concrete since it results from the solubilization of one of the cement components (Biczok, 1972 [18]; Kumar and Kumar, 1999 [19]; Sand and Bock, 1999 [20]; and Shirakawa, 1994[21]) .

Sulfur-reducing bacteria oxidize the sulfate existing in the water and transform it into hydrogen sulfides and $\mathrm{H}_{2} \mathrm{~S}$ in gaseous state. It does not affect the concrete directly; nevertheless, the $\mathrm{H}_{2} \mathrm{~S}$ is used for the Sulfur-oxidizing bacteria to produce sulfuric acid that degrades concrete chemically. This process commonly called Concrete Corrosion (Olmstead and Hamlin, 1900 [22]; Nica et al., 2000 [23]; and Roberts et al., 2002 [24]). It can be found frequently in closed structures such as: sewage systems and waste water treatment plants.

Sulfur-oxidizing bacteria are divided in two groups: (1) Neutrophilic Sulfur Oxidizing Microorganisms (NSOM); and (2) the Acidophilic Sulfur Oxidizing Microorganisms (ASOM). The oxygen required for their existence causes that they oxidize the $\mathrm{H}_{2} \mathrm{~S}$ (produced by the Sulfur-reducing bacteria), transforming it into sulfuric acid $\mathrm{H}_{2} \mathrm{SO}_{4}$, which reacts with the cement forming calcium sulfate (gypsum). Furthermore, when gypsum is combined with the hydrated aluminate of calcium, it forms sulfur-aluminate of calcium (ettringite). In addition, it can produce acetic acid, sulfates, sulfur, sulfites and polythionates, substances that affect the concrete chemically. Roberts et al., 2002 [24], reports five species of this bacteria called Thiobacillus; their main characteristics are shown in Table 3 . The first four species are NSOM and the last is ASOM. The last species (i.e., T. thiooxidans) are the group of microorganisms that causes more damage to concrete. Table 4 shows some values of concrete biodeterioration rates as a result of the action of ASOM.

\subsubsection{Fungi}

Fungi can be found almost everywhere (even in adverse atmospheres with little water and without air) as long as there is organic matter available. Generally, they survive in temperatures between 25 and $30{ }^{\circ} \mathrm{C}$. Usually, fungi found in RC surfaces are simple fungi, mold and yeast (Cho and Mori, 1995 [3]). They produce mechanical damage in the concrete micro-structure by the hyphae penetration. In addition, they deteriorate concrete chemically by the generation of organic and inorganic acids that precipitate salts.

\subsubsection{Algae and lichens}

The algae are a complex and varied vegetal group, for this reason their description and classification is not an easy task. They can survive in any habitat where there are both light and humidity; then, they can be found in the sea, humid soils and snow. Their action on concrete structures consists on taking calcium and magnesium for their metabolic processes from de cement paste generating small cavities in the concrete surface.

Lichens are the product of the symbiosis of an alga and a fungus. The fungus provides water to alga and the alga takes from the fungus inorganic substances; then, they complement each other to survive 
in very hostile environments. On concrete surfaces colonized by lichens there can be found many micro-perforations with diameters between 0,5 and 10 microns as well as perforations with diameters between 0,1 to $0,5 \mathrm{~mm}$ (Piedrahita, 2004 [2]).

\subsubsection{Organisms that erode and drill the concrete}

When concrete biodeterioration is not controlled, a series of organisms of appreciable size appears (Piedrahita, 2004 [2]). These types of organisms are found generally in tropical environments and on the concrete surface, where the biofilm has been formed. Between the organisms that erode concrete, the most representative are the mollusk (Cantera et al., 1996 [28]) whose action consists on continuously scrape the surface. Among the second class of organisms, there are the bivalves, the crustaceans and the sipunculids (Cantera et al., 1996 [28]). They make perforations of cavern type by means of chemical and physical processes.

\subsubsection{Biodeterioration control measures}

There are many preventive measures to control the action of live-organisms which depend basically on the characteristics of the species and the environmental conditions. Any procedure of countermeasures to diminish or mitigate damage must include the following actions: (1) to establish a regime of inspection or monitoring that detects immediately the appearance of the biofilm; (2) to determine the organisms that constitute the biofilm, including its density and location; (3) to elaborate a integrated plan against the involved organisms in order to solve the problem; and (4) to supervise the integrated plan and its results. Depending on the type of organism detected (i.e. step two) and the degree of damage of the structure, the integrated plans can include a combination of the following measures: (1) surface cleaning using chemical agents (i.e. biocides), biological and physical means; (2) surface painting using admixtures with biocides; and (3) replacement of concrete cover. Specific information on these counter-measures is beyond the scope of this paper, but they can be found in the literature (see Keevil et al., 1990 [29]; De Graef et al., 2000 [30]; Martinez Outeriño, 2003 [31] and Giúdice, 2003 $[32])$.

\section{Corrosion of steel reinforcement}

In addition to concrete biodeterioration, RC structural integrity may be seriously affected by steel corrosion. Steel corrosion caused by chloride ingress has been widely studied and some basic concepts are presented in this section. Tuutti, 1982 [33] proposed a model of the ingress of chlorides in concrete as function of time and depth using the Frick's second law of diffusion,

$$
\frac{\partial C}{\partial \tau}=D_{c l} \frac{\partial^{2} C}{\partial x^{2}}
$$

where, $C$ is the chloride ion concentration, $D_{c l}$ is the chloride diffusion coefficient in concrete, $\tau$ is the time and $x$ is depth in the diffusion direction. Assuming that concrete is an homogenous and isotropic material with the initial conditions: (1) when time is zero, the concentration is zero and (2) the chloride surface concentration is constant, then, the chloride ion concentration $C(x, \tau)$ at depth $x$ after time $\tau$ is:

$$
C(x, \tau)=C_{s}\left[1-\operatorname{erf}\left(\frac{x}{2 \sqrt{D_{c l} \tau}}\right)\right]
$$

where $C_{s}$ is chloride surface concentration and erf is the error function.

The threshold concentration $C_{t h}$ is defined as the chloride concentration for which the rust passive layer of steel is destroyed and the corrosion reaction begins, that instant is called initiation time $\tau_{\text {ini }}$. 
From equation 2 , when $C(x, \tau)$ is equal to $C_{t h}$ and $x$ is equal to the bar cover $c, \tau_{\text {ini }}$ is computed as:

$$
\tau_{i n i}=\frac{c^{2}\left[\operatorname{erf}^{-1}\left(1-\frac{C_{t h}}{C_{s}}\right)\right]^{-2}}{4 D_{c l}}
$$

The depth of threshold concentration $C_{t h}$ at time $\tau$ called "penetration depth of chloride threshold aggressive front" (Liang and Yang, $2005[34]) D_{t h}(\tau)$ is obtained if the concentration $C(x, \tau)=C_{t h}$ and $x=D_{t h}(\tau)$, then, equation 2 becomes:

$$
D_{t h}(\tau)=2 \sqrt{D_{c l} \tau} \operatorname{erf}^{-1}\left(1-\frac{C_{t h}}{C_{s}}\right)
$$

At time $\tau$, the corrosion density $i_{\text {corr }}(\tau)$ is expressed according to the Faraday's law as:

$$
i_{\text {corr }}(\tau)=J_{c}(\tau) n_{O_{2}} F
$$

where, $n_{O_{2}}$ is the obtained electric number of $O_{2}$ molecule participated in chemical reaction $\left(n_{O_{2}}=4\right)$, $J_{c}(\tau)$ is the diffusion flow of $O_{2}$ in concrete at time $\tau$ and $F$ is Faraday's constant, $F=96500[\mathrm{C} / \mathrm{mol}]$. On the other hand, based on electrochemistry principles, the diffusion flow of $\mathrm{O}_{2}$ in concrete is equal to (Liang et al., 2004 [35]):

$$
J_{c}(\tau)=D_{O_{2}} \frac{\partial C(x)}{\partial x}
$$

where $D_{\mathrm{O}_{2}}$ is the diffusion coefficient of $O_{2}$ in the concrete $\left[\mathrm{mm}^{2} /\right.$ year] and $x$ is the space coordinate in the diffusion direction. According to the Frick's diffusion law there is a linear variation of the oxygen concentration. Therefore, if the oxygen concentration on the surface is $C_{O_{2}}=8.93 \times 10^{-10}\left[\mathrm{~mol} / \mathrm{mm}^{3}\right]$ and at the depth $D_{t h}(\tau)$ the concentration is $C_{s t}=0$ (Liang et al., 2004 [35]),

$$
\frac{\partial C(x)}{\partial x}=\frac{C_{O_{2}}-C_{s t}}{D_{t h}(\tau)}
$$

Replacing equations 6 and 7 into equation 5 yields to:

$$
i_{\text {corr }}(\tau)=\frac{n_{\mathrm{O}_{2}} F D_{\mathrm{O}_{2}} C_{\mathrm{O}_{2}}}{D_{t h}(\tau)}
$$

On the other hand, according to Faraday's law, the product of steel corrosion during time $d \tau$ is:

$$
d W_{\tau}=\frac{i_{c o r r}(\tau)}{n_{a} F} M A_{a}(\tau) d \tau
$$

where $d W_{\tau}$ is the amount of corrosion products in grams at time $d \tau, M$ is the atomic weight of $F e=55.85[\mathrm{~g} / \mathrm{mol}], n_{a}$ is the electric charge of iron ion $\left(n_{a}=2\right)$ and $A_{a}(\tau)$ is the corrosion surface area of steel in concrete at time $\tau$ considering a $1[\mathrm{~mm}]$ unit length bar (Figure 2), and is equal to:

$$
A_{a}(\tau)=d \cos ^{-1}\left(\frac{d+2 c-2 D_{t h}(\tau)}{d}\right)
$$

where $d$ is the initial bar diameter in [mm] and $c$ is the cover thickness in [mm]. Niu et al., 1996 [36] proposed an equation for calculating $D_{O_{2}}$ as a function of the concrete compressive strength $f_{c u}^{\prime}$ in $\left[\mathrm{N} / \mathrm{mm}^{2}\right]\left(f_{c u}^{\prime}\right.$ is obtained from the test over a concrete cube sample):

$$
D_{O_{2}}=3.1536 \times 10^{5}\left(\frac{32.15}{f_{c u}^{\prime}}-0.44\right)\left[\frac{\mathrm{mm}^{2}}{\text { year }}\right]
$$


If $\tau_{w}$ is the time of full corrosion, this occurs when $A_{a}(\tau)$ is equal to total surface area of the steel bar (i.e., $A_{a}(\tau)=\pi d$ ), then, for $\tau_{w} \geq \tau$, the amount of corrosion products, $W(\tau)$, is obtained by replacing equation 8 into equation 9 and integrating with respect to time:

$$
W(\tau)=\left[\begin{array}{ll}
0 \text { grams } & \text { if } \tau_{\text {ini }} \geq \tau \\
k D_{O_{2}} \int_{\tau_{\text {ini }}}^{\tau}\left[\frac{A_{a}(\tau)}{D_{t h}(\tau)}\right] d \tau & \text { if } \tau_{w} \geq \tau>\tau_{\text {ini }}
\end{array}\right]
$$

where $k=n_{O_{2}} C_{O_{2}} M / n_{a}=7.125 \times 10^{-8}\left[\mathrm{~g} / \mathrm{mm}^{3}\right]$. Finally, if $\tau>\tau_{w}, A_{a}(\tau)=\pi d$ and $D_{t h}(\tau)=c+d$, then,

$$
W(\tau)=\left[\begin{array}{ll}
0 \text { grams } & \text { if } \tau_{i n i} \geq \tau \\
k D_{O_{2}} \int_{\tau_{i n i}}^{\tau} \frac{A_{a}(\tau)}{D_{t h}(\tau)} d \tau & \text { if } \tau_{w} \geq \tau>\tau_{i n i} \\
k D_{O_{2}}\left(\int_{\tau_{\text {ini }}}^{\tau_{w}} \frac{A_{a}(\tau)}{D_{t h}(\tau)} d \tau+\frac{\pi d}{c+d} \int_{\tau_{w}}^{\tau} d \tau\right) & \text { if } \tau>\tau_{w}
\end{array}\right]
$$

Based on equation 13, it is then possible to compute the effective diameter of the bar as function of time as follows:

$$
d_{b a r}(\tau)=d_{0}\left(1-\frac{W(\tau)}{W_{0}}\right)
$$

where $d_{b a r}(\tau)$ is the diameter of the bar at time $\tau, d_{0}$ is the bar initial diameter, $W(\tau)$ is the amount of corrosion products in $[\mathrm{g}]$ by $1[\mathrm{~mm}]$ of length at time $\tau$ calculated by equation 13 and $W_{0}$ is the initial weight in $[\mathrm{g}]$ by $1[\mathrm{~mm}]$ length.

\section{Coupled deterioration model}

The coupled model presented in this section takes into account three effects (Figure 3): (1) corrosion induced by chloride ingress; (2) cracking as a result of corrosion products; and (3) reduction of concrete cover caused by biodeterioration. In the first part of this section, the corrosion model presented in previous section will be modified to include the cracking. Afterwards, a time-dependent biodeterioration rate function is obtained by using a fuzzy logic inference system. Finally, all three effects are coupled into one single model.

\subsection{RC cracking as a result of corrosion products}

Once corrosion starts there are stresses resulting from the expansion produced by corrosion. Then, in order to take into account this effect, Liu and Weyers,1998 [11] proposed a model to find the time to crack initiation, $\tau_{c r}$, that is function of the amount of rust products. They defined the amount of critical rust products $W_{\text {crit }}[\mathrm{g}]$ as the amount for which all free spaces between the steel bar and the concrete are filled and the cracking begins. It can be calculated as:

$$
W_{\text {crit }}=\frac{\rho_{\text {steel }}}{\rho_{\text {steel }}-0.57 \rho_{\text {rust }}}\left(W_{\text {porous }}+W_{\text {Expand }}\right)
$$

where $\rho_{\text {steel }}$ is the density $\left[\mathrm{g} / \mathrm{mm}^{3}\right]$ of reinforced steel, $\rho_{\text {rust }}$ is the density of corrosion products, $W_{\text {porous }}$ is the amount of corrosion products necessary to fill the porous zone around the steel/concrete interface and is defined as:

$$
W_{\text {porous }}=\pi \rho_{\text {rust }} t_{\text {por }} d
$$

where $t_{p o r}$ is the thickness of porous band around the steel concrete interface and $d$ is the diameter of the steel bar. Besides, $W_{\text {Expand }}$ is the amount of corrosion products needed to fill in the space due to the expansion of the concrete around the reinforcement; this is:

$$
W_{\text {Expand }}=\pi \rho_{\text {rust }}\left(d+2 t_{\text {por }}\right) t_{\text {crit }}
$$


where $t_{\text {crit }}$ is the thickness of corrosion products needed to generate the tensile stresses (Liu and Weyers, 1998 [11]) and it is computed as:

$$
t_{c r i t}=\frac{c f_{t}^{\prime}}{E_{c}}\left(\frac{k^{2}+l^{2}}{l^{2}-k^{2}}+\nu_{c}\right)
$$

where $f_{t}^{\prime}$ is the tensile strength of concrete, $E_{c}$ is the elastic modulus of concrete, $k=\left(d+2 t_{p o r}\right) / 2$, $l=c+\left(d+2 t_{\text {por }}\right) / 2$ and $\nu_{c}$ is Poisson's ratio of concrete.

The amount of corrosion products $W(\tau)$ is zero if the age of the concrete $\tau$ is less than $\tau_{\text {ini }}$ (Figure 4a). When $\tau \leq \tau_{s p}$, the value of $D_{\mathrm{O}_{2}}$ is obtained by using equation 11 . The time to severe cracking, $\tau_{s p}$, is equal to (Vu and Stewart, 2005 [12] and Vu et al., 2005 [13]):

$$
\tau_{s p}=\tau_{c r}+\tau_{p r}
$$

where $\tau_{p r}$ is the time of crack propagation. Based on experimental data obtained from accelerated corrosion tests with a corrosion rate of $i_{\operatorname{corr}(a c c)}=100 \mu \mathrm{A} / \mathrm{cm}^{2}$, Vu et al (2005) [13] found that the accelerated time to crack propagation in hours can be estimated as:

$$
\tau_{p r(a c c)}=\xi(c / w c)^{\lambda}
$$

where $c$ is the cover in $\mathrm{mm}, w c$ is the water/cement ratio, and $\xi$ and $\lambda$ are parameters that depend on the limit crack width. For instance, when $c w_{l i m}=0.5 \mathrm{~mm}, \xi=225$ and $\lambda=0.29$ (Vu et al., 2005 [13]). Since equation 20 was obtained from accelerated tests, a correction factor, $k_{R}$, has been deduced by $\mathrm{Vu}$ et al. (2005) [13], based on the experimental values obtained by Alonso et al (1998) [37] as:

$$
k_{R} \approx 0.95\left[\exp \left(-\frac{0.3 i_{\operatorname{corr}(a c c)}}{i_{\operatorname{corr}(\text { real })}}\right)-\frac{i_{\operatorname{corr}(a c c)}}{2500 i_{\text {corr }(\text { real })}}+0.3\right]
$$

where $i_{\text {corr (real) }}$ corresponds to the real corrosion rate in $\mu \mathrm{A} / \mathrm{cm}^{2}$. Therefore, the time to crack propagation in years is:

$$
\tau_{p r}=k_{R} \frac{0.0114}{i_{\text {corr }(\text { real })}} \tau_{p r(a c c)}
$$

After cracking begins (i.e., $\tau>\tau_{s p}$ ) the diffusion coefficient $D_{O_{2}}$ becomes time-dependent and a linear behavior is assumed. Consider that at time $\tau_{n}$ (with $\tau_{n} \gg \tau_{s p}$; e.g. $\tau_{n}=500$ years) the oxygen concentration at the steel surface (i.e., $C_{n O_{2}}$ ) is closer to the oxygen concentration at the concrete surface $C_{O_{2}}$ (i.e., $C_{n O_{2}} \approx C_{O_{2}}$ ). Then substituting these values into Frick's second law (equation 2), it is possible to compute a new oxygen diffusion coefficient at time $\tau_{n}$, as:

$$
D_{n O_{2}}\left(\tau_{n}\right)=\frac{c^{2}}{4 \tau_{n}\left[\operatorname{erf}^{-1}\left(1-\frac{C_{n O_{2}}}{C_{O_{2}}}\right)\right]^{2}}
$$

and the diffusion coefficient of oxygen in the concrete $\left(D C_{O_{2}}\right)$ at time $\tau$ becomes (Figure $4 \mathrm{~b}$ ):

$$
D C_{O_{2}}(\tau)=\left[\begin{array}{ll}
D_{O_{2}} \\
D_{O_{2}}+\left(\frac{D_{O_{2}}-D_{n O_{2}}}{\tau_{s p}-\tau_{n}}\right)\left(\tau-\tau_{s p}\right) & \text { if } \tau>\tau_{s p}
\end{array}\right]
$$

then, substituting equation 24 into 13, the amount of corrosion products when considering the RC 
cracked, $W_{\text {crack }}(\tau)$, in $[\mathrm{g}]$ by $1 \mathrm{~mm}$ of length at time $\tau$ is given by:

$$
W_{\text {crack }}(\tau)=\left[\begin{array}{ll}
0 \text { grams } & \text { if } \tau_{\text {ini }} \geq \tau \\
k \int_{\tau_{\text {ini }}}^{\tau} \frac{D C_{O_{2}} A_{a}(\tau)}{D_{t h}(\tau)} d \tau & \text { if } \tau_{w} \geq \tau>\tau_{\text {ini }} \\
k\left(\int_{\tau_{\text {ini }}}^{\tau_{w}} \frac{D C_{O_{2}}(\tau) A_{a}(\tau)}{D_{t h}(\tau)} d \tau+\frac{\pi d}{c+d} \int_{\tau_{w}}^{\tau} D C_{O_{2}}(\tau) d \tau\right) & \text { if } \tau>\tau_{w}
\end{array}\right]
$$

The consequences of cracking on the corrosion rate is not easy to evaluate; Figure 5 presents several models. In the first model, the time-variant corrosion rate has been computed by using the values reported by $\mathrm{Vu}$ et al. (2005) [13]. In this model, corrosion rate remains constant during the first year, after which, the formation of rust products on the steel surface reduces this rate substantially. The second model considers a reduction of corrosion rate, from the corrosion initiation time, $\left(\tau_{\text {ini }}\right)$ until the time of full corrosion, $\left(\tau_{w}\right)$. After this point, the corrosion rate remains constant (see also Figure 4). In the third case, the model includes concrete cracking and assumes that the change of the diffusion coefficient of concrete (equation 20) begins only after the time to crack initiation, $\left(\tau_{c r}\right)$. After this point, diffusion grows due to the increase in the diffusion oxygen coefficient. The last case is similar to the previous one but the effect of cracking has only an important impact when the crack width reaches a limit value of $c w_{l i m}=0.5 \mathrm{~mm},\left(\tau_{s p}\right)$. In this case, the corrosion rates are lower than in the third case.

The first two models presented in Figure 5 do not take into account concrete cracking to estimate corrosion rate, while the last two do. In this paper the last model was used to compute the amount of corrosion products. It is important to note that the corrosion rates used in this paper are within the range suggested by EN 206 (Geocisa and Torroja Institute, 2002 [38]) for corrosion induced by chloride ingress in tidal zones.

\subsection{Time-dependent biodeterioration rate function}

Biodeterioration is a very complex process where many classes of organisms, environmental variables and other deteriorating processes interact. Computing the $\mathrm{RC}$ time-dependent biodeterioration rate is a crucial aspect for the accuracy of the numerical model. However, to the authors knowledge, no much work have been done in this field and there is not yet a robust model of this process. As no sufficient data are available to perform appropriate statistical analysis, the application of probability theory is not possible. Thus, non precise data is considered based on existing experimental reports (Table 4). The proposed model is based on fuzzy inference, which is a valuable tool for managing situations where information about a process can only be described conceptually or there is not enough data to build a

robust statistical model. Then, based on fuzzy logic, a model to obtain a time-dependent function of the biodeterioration rate is proposed.

Conceptually, the process can be divided into three stages (Figure 6):

1. $R C$ immunity: in this stage, due the concrete high alkalinity ( $p H$ between 11 and 13), the organisms cannot survive nor adhere to it; therefore, the RC is immune to biological damage.

2. Biofilm formation: the presence of $\mathrm{CO}_{2}$ in the atmosphere causes carbonation, which in turn leads to a reduction of the $p H$ of the RC surface (until approximately 9). In addition, the erosive action of the water and/or the friction with other materials generate certain roughness on the concrete surface that allows microorganisms to adhere forming the biofilm. Experimental evidence has shown that microorganisms can also ingress into concrete by a diffusion process alterating the concrete microstructure (Ribas and Pinheiro, 2006).

3. Active biodeterioration of concrete: in this stage, the concrete $p H$ continues decreasing, by the joint action of carbonation and organisms until it reaches a value of $p H<5$. The $\mathrm{RC}$ surface is highly deteriorated and the cracks have an important size. All those conditions make possible that other organisms also stick to biofilm on the surface contributing to RC chemical deterioration. When the concrete is cracked, some organisms like the endolithic cells, algae and fungi ingress 
into cracks, generating tensile stresses that deteriorate the concrete by increasing the crack size. Crack formation can also be promoted as a result of the weakened on the concrete microstructure caused by fungi and other microorganisms that might have already enter into concrete matrix by diffusion.

Based on the conceptual model the membership functions for the age of the structure (i.e., in time units [years], $\tau$ ) and the biodeterioration rate $\gamma$ [mm/year] can be defined. Then, The structure life can be divided in two stages:

1. Initial Age: at this age, microorganisms can hardly live on the surface of the concrete because it is even and the $p H$ of concrete is high.

2. Active Biodeterioration Age: at this stage, the biodeterioration is active because the surface offers optimal conditions for colonization of microorganisms.

These stages are represented by membership functions of sigmoidal form (see Figure 7a):

$$
\mu_{\text {age }}(\tau, a, b)=\frac{1}{1+\exp (-a(\tau-b))}
$$

where $\tau$ is the time in years and $a, b$ are constants that define the shape of the function. In addition, it is necessary to define two membership functions for the corresponding biodeterioration rate $\gamma$. The first corresponds to the initiation of the biodeterioration process for which the maximum membership value assigned is $\gamma_{i n i}=0$ [mm/year]. Then, in this case the modified Gaussian function that describes the initial biodeterioration rate membership is given by (see Figure $7 \mathrm{~b}$ ):

$$
\mu_{\gamma_{1}}(\gamma, \sigma)=\left[\begin{array}{ll}
\exp \left(-\frac{1}{2}\left[\frac{\gamma}{\sigma}\right]^{2}\right) & \text { if } \gamma \geq 0 \\
0 & \text { otherwise }
\end{array}\right]
$$

where $\sigma$ is a shape parameter. The second function corresponds to the time within which biodeterioration is active; thus, based on the values presented in Table 4, the average active biodeterioration rate, $\gamma_{a v}$, is assigned to the maximum membership value. In this case, the membership function that describes the corrosion rate is:

$$
\mu_{\gamma_{2}}\left(\gamma, \gamma_{a v}, \sigma\right)=\exp \left(-\frac{1}{2}\left[\frac{\gamma-\gamma_{a v}}{\sigma}\right]^{2}\right)
$$

Figure 7 illustrate these functions for the following parameters: $a_{\tau_{\text {ini }}}=-0.8$ and $b_{\tau_{\text {ini }}}=6.5$ for the Initial Age; $a_{\tau_{a c t}}=0.7$ and $b_{\tau_{a c t}}=12$ for the Active Biodeterioration Age; $\sigma_{\gamma_{i n i}}=0.1$ for the Initial Biodeterioration Rate; and $\gamma_{a v}=2.5 \mathrm{~mm} / \mathrm{yr}$ and $\sigma_{\gamma_{a c t}}=0.4$ for the Active Biodeterioration Rate.

The rules used for the fuzzy inference system are:

1. If the structure is in the initial age, then the biodeterioration rate is the initial.

2. If the structure is in the active biodeterioration age, then the biodeterioration rate is active.

Based on these rules a response surface can be determined as follows:

$$
S(\tau, \gamma)=\max \left(\begin{array}{c}
\mu_{a g e_{1}}\left(\tau, a_{\tau_{\text {ini }}}, b_{\tau_{\text {ini }}}\right) \mu_{\gamma_{1}}\left(\gamma, \sigma_{\gamma_{\text {ini }}}\right) \\
\mu_{\text {age }}\left(\tau, a_{\tau_{\text {act }}}, b_{\tau_{a c t}}\right) \mu_{\gamma_{2}}\left(\gamma, \gamma_{a v}, \sigma_{\gamma_{a c t}}\right)
\end{array}\right)
$$

where $S(\tau, \gamma)$ is the surface generated by the maximum of products composition, $\mu_{\text {age }}\left(\tau, a_{\tau_{\text {ini } i}}, b_{\tau_{\text {ini }}}\right)$ is the membership function corresponding to concrete initial age, $\mu_{a g e_{2}}\left(\tau, a_{\tau_{\text {act }}}, b_{\tau_{\text {act }}}\right)$ to active biodeterioration age, $\mu_{\gamma_{1}}\left(\gamma, \sigma_{\gamma_{\text {ini }}}\right)$ to initial biodeterioration rate and $\mu_{\gamma_{2}}\left(\gamma, \gamma_{a v}, \sigma_{\gamma_{\text {act }}}\right)$ to active biodeterioration rate. The surface generated by equation 29 is shown in Figure 8a. Finally, by using the 
strategy of the center of gravity for the surface defuzzification, it is possible to obtain a time-dependent biodeterioration rate function, $\gamma(\tau)$, as (Figure $8 \mathrm{~b}$ ):

$$
\gamma(\tau)=\frac{\int \gamma \cdot S(\tau, \gamma) d \gamma}{\int S(\tau, \gamma) d \gamma}
$$

The advantage of this solution is that it provides an estimation of the time-dependent change of the biodeterioration rate, that depends on the expert's knowledge. Hence the expert has to define the conceptual model of the problem as presented above. Moreover, he/she determines the form of the membership functions, since, he/she has to assign values to the variables $a, b, \gamma_{a v}$ and $\sigma$ based on his/her expertise. For example, an expert can define the membership functions of the biodeterioration rate considering environmental factors and nutrients availability of determinate place, and the age membership functions taking into account the type of cement or the condition of the structure at a given time. It is important to stress on the fact that the biodeterioration rate function can be updated permanently by modifying the membership functions based on field measurements and experimental data.

\subsection{Coupled model}

Due to action of live organisms, the thickness of the concrete cover is a time-dependent function. Then, the thickness at time $\tau$ (i.e., cover $(\tau)$ ) is calculated as:

$$
\operatorname{cover}(\tau)=c-\int_{0}^{\tau} \gamma(\tau) d \tau
$$

where $c$ is the cover at $\tau=0$ and $\gamma(\tau)$ corresponds to the biodeterioration rate function showed in Figure $8 \mathrm{~b}$. Then, the initiation time $\tau_{i n i}$ is calculated by replacing equation 31 into equation 3 ,

$$
\tau_{i n i}=\frac{\operatorname{cover}(\tau)^{2}\left[\operatorname{erf}^{-1}\left(1-\frac{C_{t h}}{C_{s}}\right)\right]^{-2}}{4 D_{c l}}
$$

For time $\tau>\tau_{\text {ini }}$, the advance of the aggressive corrosion front, $D_{t h}(\tau)$ (equation 4 ), and the reduction of steel area grow rapidly affecting considerably the properties of the structural member. Therefore, equation 10 is modified simply by making the cover thickness a function of time. That is:

$$
A_{a m}(\tau)=d \cos ^{-1}\left(\frac{d+2 \operatorname{cover}(\tau)-2 D_{t h}(\tau)}{d}\right)
$$

where $A_{a m}(\tau)$ is corroded surface area of the reinforcement at time $\tau$ (taking $1 \mathrm{~mm}$ unit length) when the biodeterioration process is taken into account. Consequently, the amount of corrosion products $W_{m}(\tau)$, which is function of $A_{a m}(\tau)$, can be expressed as:

$$
W_{m}(\tau)=\left[\begin{array}{ll}
0 \text { grams } & \text { if } \tau_{i n i} \geq \tau \\
k \int_{\tau_{i n i}}^{\tau} \frac{D C_{O_{2}} A_{a m}(\tau)}{D_{t h}(\tau)} d \tau & \text { if } \tau_{w} \geq \tau>\tau_{i n i} \\
k\left(\int_{\tau_{i n i}}^{\tau_{w}} \frac{D C_{O_{2}}(\tau) A_{a m}(\tau)}{D_{t h}(\tau)} d \tau+\frac{\pi d}{c+d} \int_{\tau_{w}}^{\tau} D C_{O_{2}}(\tau) d \tau\right) & \text { if } \tau>\tau_{w}
\end{array}\right]
$$

On the whole, the proposed model couples three processes: (1) steel corrosion; (2) concrete cracking; and (3) biodeterioration. The flow diagram that summarizes the entire procedure is presented in Figure 9. The ultimate purpose of the model is to compute the reduction of steel reinforcement area of the 
$\mathrm{RC}$ element. As it will be shown in the numerical example, this approach to RC biodeterioration can be used to make better estimates of structural reliability and is an important tool for intervention and rehabilitation purposes.

\section{$5 \quad$ Numerical Example}

\subsection{Basic considerations and assumptions}

In this section, the coupled model described in the previous section is illustrated with a numerical example. The goal of this example is to compute the probability of failure of a seaport reinforced concrete pile in terms of its curvature ductility capacity. The pile showed in Figure 10 is part of a port structural system subjected to axial loading produced by the loading and unloading of containers on the platform (see Figure 10a). The port is located in a tropical region where the environmental conditions make the structure susceptible to biological deterioration. The geometric characteristics of the pile are presented in Figure 10b.

For structures immersed in the sea, there are three zones (see figure 10a), with different surface chloride concentration and availability of oxygen and water for which the cinematic of the corrosion process is different (Luping and Andersen, 2000 [40]). These are: (1) the Submerged zone, (2) the Splash and tidal zone, and (3) the Atmospheric zone. In the first zone, the surface chloride concentration is higher that in the other zones, but the risk of corrosion and biodeterioration are low because the oxygen and light are not available. In the splash and tidal zone, the RC surface is exposed to wetting and drying cycles that provide the optimal conditions (chlorides, water and oxygen) for corrosion to initiate. Furthermore, the existence of light, nutrients and water in sufficient quantities promotes the appearance of the biofilm. It is widely accepted that the highest risks of corrosion and biodeterioration occur in this zone. Finally, in the last region the wind is the main source of chlorides and the water available is low, thus, the risks of corrosion and biodeterioration are small. Therefore, the present example focuses on the splash and tidal zone.

The following assumptions about the problem have been made:

- The density of steel reinforcement is assumed deterministic $\left(\rho_{\text {steel }}=8000 \mathrm{~kg} / \mathrm{m}^{3}\right)$,

- The tensile strength of concrete is given by a percentage of its compressive strength (i.e. $f_{t}^{\prime}=$ $\left.0.10 f_{c}^{\prime}\right)$. Perfect correlation between tensile and compressive strengths is assumed.

- In order to estimate the time to severe cracking, a limit crack width of $c w_{l i m}=0.5 \mathrm{~mm}$ has been chosen.

- The water/cement ratio is calculated by using the Bolomey's formula.

- The corrosion of steel is assumed to be uniform.

- The deterioration process is continuous, i.e. there is not maintenance.

\subsection{Reliability problem formulation}

Ductility capacity is the structural ability to sustain, without failure, deformations well beyond the elastic limit. In this case, the curvature ductility capacity $\mu_{\phi}$ is equal to,

$$
\mu_{\phi}=\frac{\phi_{u}}{\phi_{y}}
$$

where $\phi_{u}$ and $\phi_{y}$ are the ultimate and yield curvatures respectively. Stress-strain relationship for the steel follows an elasto-plastic model and for concrete it was assumed an inelastic behavior (Kent and 
Park, 1971 [44]). In this application, the failure probability is calculated with respect to the following limit state function:

$$
g\left(\mu_{\phi_{i n i}}, \mu(\tau)\right)=\theta \mu_{\phi_{i n i}}-\mu(\tau)
$$

where $\theta \mu_{\phi_{i n i}}$ corresponds to a fraction (i.e., $\theta$ ) of the initial ductility, $\mu_{\phi_{i n i}}$, and $\mu(\tau)$ is the ductility of the pile at time $\tau$.

Three variations of the same limit state function were considered based on a fraction of the structural initial capacity, $\mu_{\phi_{i n i}}, \theta$ : (1) $\theta=0.75$; (2) $\theta=0.50$; and (3) and $\theta=0.25$. The probabilistic models of the variables used are shown in Table 5 . The reliability was calculated by using a "pointin-time" analysis by using using the first-order second-moment reliability method FORM, which is conservative (upper bound) (Stewart and Val, $1999[45]$ ).

\subsection{Results of the model}

The failure probability of the three limit state functions for various average active biodeterioration rates, $\left(\gamma_{a v}\right)$, is presented in Figure 11. It can be observed that the shape of the fragility curves, i.e., slope and time to failure failure (i.e., $p_{f}=1$ ) depend upon: (1) the average active biodeterioration rate and (2) the limit state function (i.e., defined as a fraction of the initial ductility $\theta$ ). Comparing the cases with and without biodeterioration it is observed that the overall behavior is similar, but all failure times with biodeterioration occur earlier. In addition, as the average active biodeterioration rate grow, the time to failure decreases and the slope of the fragility curves increase. It can be observed also that the overall effect of $\gamma_{a v}$ is larger when the fraction of the initial ductility $\theta$ decreases.

The relationship between the average active biodeterioration rate and the time required to reach failure are plotted in Figure 12. This figure shows that for all limit state functions, the time to failure grows as $\gamma_{a v}$ decreases. This time period also grows as $\theta$ decreases. For instance, for $\theta=0.75$, the time to failure is 40 years for $\gamma_{a v}=2.5 \mathrm{~mm} / \mathrm{yr}$, and 80 years for $\gamma_{a v}=0 \mathrm{~mm} / \mathrm{yr}$ respectively. An inverse analysis can also be made from the data presented in Figure 12; for a predefined life-cycle it is possible to estimate the average biodeterioration rate required to reach a given limit state. For example, if a time window of 60 years is selected, a $\gamma_{a v}=0.9 \mathrm{~mm} / \mathrm{yr}$ is required to meet the failure limit condition as defined by a $75 \%$ of its initial curvature ductility (i.e., $\left(p_{f}\right)_{\theta=0.75}=1$ ). The same values for $\theta=0.5$ and $\theta=0.25$ are $\gamma_{a v}=1.3 \mathrm{~mm} / \mathrm{yr}$ and $\gamma_{a v}=1.7 \mathrm{~mm} / \mathrm{yr}$, respectively (Figure 12).

Finally, it is important to notice the effect of deterioration in the reduction of the ductility capacity of the structural component. The change of ductility with time for a probability of failure equal to $p_{f}=1$ and $p_{f}=0.5$, and for various average biodeterioration rates is shown in Figure 13. As expected, the ductility capacity decreases with time, but if biodeterioration is not considered, the structural ductility capacity is larger than in the case where this effect is included. For example, if biodeterioration is not taken into account, the time required to reach failure, for $\theta=0.75$, will be 80 years. However, when considering biodeterioration this time becomes $t\left(\gamma_{a v}=0.5\right)_{\theta=0.75}=69$ years $(13 \%)$ and $t\left(\gamma_{a v}=2.5\right)_{\theta=0.75}=40$ years $(50 \%)$. It is evident from the results that preventive maintenance against biodeterioration is paramount to extend the structural life.

\section{Conclusions}

Modeling the effects of biodeterioration in RC structures should to be explicitly included as part of infrastructure planning and design, in particular, when structures are located in aggressive environments. Biodeterioration might affect structural performance significantly causing an important reduction in the lifetime of the structure. The proposed model couples three processes: (1) steel corrosion; (2) concrete cracking; and (3) biodeterioration. This coupling process is used to compute the reduction of steel reinforcement area and concrete cross section as a function of time. Furthermore, a fuzzy inference system based on experimental data and expert opinions was used to model the biodeterioration rate which is an essential part of the integrated model. The fuzzy model is a very convenient tool which combines data bases with expert knowledge about the local environmental variables. The 
proposed model is illustrated by studying the effects of biodeterioration in the ductility capacity of sea port piles. A difference between $13 \%$ and $50 \%$ in the structural life was observed. The high variability is related to the value of $\gamma_{a v}$, which should be a subject of further experimental research.

\section{Appendix A - Glossary}

\begin{tabular}{ll}
\hline \multicolumn{1}{c}{ Term } & Description \\
\hline Aerobe: & organisms that require oxygen for their vital processes. \\
Aerotolerant anaerobes: & organisms that not require oxygen, but are not affected by their \\
& exposure to air. \\
organisms that are unable to use oxygen for their vital processes. & these are organisms that do not need organic carbon to survive \\
bnaerobe: & because their carbon source is the inorganic $C O_{2}$ and some car- \\
Autotroph: & bonates. \\
& fundamental unit of a living matter. \\
& specie that lives inside the rocks or RC (thanks to previous perfo- \\
rations or cracks). & unlike autotroph organisms, they need organic carbon for their \\
Endolith: & survival. \\
Heterotroph: & any of the threadlike filaments forming the mycelium of a fungus \\
any organism of microscopic size. & the vegetative part of a fungus consisting of a mass of branching \\
Microorganism: & threadlike hyphae. \\
Mycelium: & a filamentous fungus that forms hypha and mycelium; produces a \\
superficial growth on various kinds of damp or decaying organic \\
mold or mould:
\end{tabular}

\section{References}

[1] Santander C F, Sánchez-Silva M, Design and maintenance-program optimization for large infrastructure systems. Structure and Infrastructure Engineering. (To be published), 2006.

[2] Piedrahita A. Patologías por acciones biológicas: Bioerosión del muelle de Buenaventura, Colombia. Noticreto 2004; 70:42-50. (In Spanish)

[3] Cho K, Mori T. A newly isolated fungus participates in the corrosion of concrete sewer pipes. Water Science and Technology 1995; 31:263-71.

[4] Morton RL, Yanko WA, Grahom DW, Arnold RG. Relationship between metal concentrations and crown corrosion in Los Angeles County sewers. Research Journal of Water Pollution Control Federation 1991; 63:789-98.

[5] CC Technologies Laboratories, Inc. Corrosion Costs and Preventive Strategies in the United States, Report by to Federal Highway Administration (FHWA), Office of Infrastructure Research and Development, Report FHWA-RD-01-156, September 2001.

[6] Mori Y, Ellingwood BR. Reliability-based life prediction of structures degrading due to environment and repeated loading. In: Lemaire M, Favre JL, Mébarki A, editors. Applications of 
Statistics and Probability: Civil Engineering Reliability and Risk Analysis, Paris: Balkema; 1995, p. 971-6.

[7] Clifton JR. Predicting the Service Life of Concrete. ACI Materials Journal 1993; 90:611-7.

[8] Mori Y, Ellingwood BR. Reliability-Based Service-Life Assessment of Aging Concrete structures. Journal of structural engineering, ASCE 1993; 119:1600-21.

[9] Thoft-Christensen P. Deterioration of concrete structures. In: Proceedings of the First International Conference on Bridge Maintenance, Safety and Management, IABMAS '02, Barcelona, Spain, 2002. p. 1-8.

[10] Liu Y. Modeling the Time-to-Corrosion Cracking of the Cover Concrete in Chloride Contaminated Reinforced Concrete Structures. Ph.D. Dissertation, Virginia Polytechnic Institute and State University. Blacksburg, Virginia; 1996.

[11] Liu Y, Weyers RE. Modeling the Time-to-Corrosion Cracking of the Cover Concrete in Chloride Contaminated Reinforced Concrete Structures. ACI Materials Journal 1998; 95:675-81.

[12] Vu KAT, Stewart MG. Predicting the Likelihood and Extent of Reinforced Concrete CorrosionInduced Cracking. Journal of Structural Engineering ASCE 2005; 131:1681-89.

[13] Vu KAT, Stewart MG, Mullard J. Corrosion-Induced Cracking: Experimental data and predictive models. ACI Structural Journal 2005; 102:719-26.

[14] Schiessl P, Raupach M. Laboratory Studies and Calculations on the Influence of Crack Width on Chloride-Induced Corrosion of Steel in Concrete. ACI Materials Journal 1997; 94:56-62.

[15] Hueck HJ. The biodeterioration of materials as part of hylobiology. Material und Organismen $1965 ; 1: 5-34$.

[16] Gaylarde C. Biodeterioração de Monumentos: A Importância de Cianobactérias. In: Jornadas Iberoamericanas Sobre Biodeterioro del Patrimonio Cultural Iberoamericano, Prevención, Restauración, Preservación. Cartagena, Colombia, 2003. (In Portuguese).

[17] Gaylarde C, Ribas Silva M, Warscheid Th. Microbial impact on building materials: an owerview. Materials and structures 2003; 36:342-52.

[18] Biczok I, Corrosion y Protección del Hormigón. Trad. Emílio D’Ocion Asensi. Bilbao. España: Ediciones URMO, 1972. p. 198-318. (In Spanish)

[19] Kumar R, Kumar AV, Biodeterioration of stone in tropical environments - an overview. 1.ed. E.U.A.: J. Paul Getty Trust, 1999. 85p.

[20] Sand W, Bock E, Biodeterioration of mineral materials by microorganisms - biogenic sulfuric and nitric acid corrosion of concrete and natural stone. Geomicrobiology Journal, UK, v.9, p. 129-138, 1991a.

[21] Shirakawa MA, Estudo da biodeterioração do concreto por Thiobacillus. São Paulo: Instituto de Pesquisas energéticas e nucleares - Autarquia associada à Universidade de São Paulo, 1994. 121p. (In Portuguese).

[22] Olmstead WM, Hamlin H. Converting portions of the Los Angeles outfall sewer into a septic tank. Engineering News 1900; 44:317.

[23] Nica D, Davis JL, Kirby L, Zuo G, Roberts DJ. Isolation and characterization of microorganisms involved in the biodeterioration of concrete in sewers. International Biodeterioration and Biodegradation 2000; 46:61-8. 
[24] Roberts DJ, Nica D, Zuo G, Davis JL. Quantifying microbially induced deterioration of concrete: initial studies. International Biodeterioration and Biodegradation 2002; 49:227-34.

[25] Mori T, Nonaka T, Tazaki K, Koga M, Hikosaka Y, Noda S. Interactions of nutrients, moisture, and $\mathrm{pH}$ on microbial corrosion of concrete sewer pipes. Water Research 1992; 26:29-37.

[26] Ismail N, Nonaka T, Noda S, Mori T. Effect of carbonation on microbial corrosion of concrete. Journal of Construction Management and Engineering 1993; 20:133-8.

[27] Davis JL. Characterization and modeling of microbially induced corrosion of concrete sewer pipes. Ph.D. Dissertation, University of Houston. Houston, Texas; 1998.

[28] Cantera J, Neira R, Ricaurte C. Bioerosión. Inovación y ciencia 1996; 5:24-33. (In Spanish).

[29] Keevil CW, Mackerness CW, Colbourne JS. Biocide treatment of biofilms. International Biodeterioration 1990; 26:169-79.

[30] De Graef B, De Windt W, De Belie N, Verstraete W. Bacterial cleaning of concrete surfaces. In: Proccedings of the First International RILEM Workshop Microbial Impact on Building Materials. São Paulo. Brazil, 2000.

[31] Martínez Outeriño P. Manejo integrado contra plagas. In: Jornadas Iberoamericanas Sobre Biodeterioro del Patrimonio Cultural Iberoamericano, Prevención, Restauración, Preservación. Cartagena, Colombia, 2003. (In Spanish).

[32] Giúdice CA. Patrimonio cultural: limpieza, consolidación y tratamiento con biocidas. In: Jornadas Iberoamericanas Sobre Biodeterioro del Patrimonio Cultural Iberoamericano, Prevención, Restauración, Preservación. Cartagena, Colombia, 2003. (In Spanish).

[33] Tuutti K. Corrosion of steel in concrete. Swedish Cement and Concrete Institute 1982.

[34] Liang MT, Yang RJ. Theoretical elucidation on the on-site measurements of corrosion rate of reinforcements. Construction and building materials 2005; 19:175-80.

[35] Liang MT, Jin WL, Yang RJ, Huang NM. Predeterminate model of corrosion rate of steel in concrete. Cement and concrete research 2005; 35:1827-1833.

[36] Niu DT, Wang LK, Wang QL. Determination of the diffusion coefficient of dioxidation in concrete. Journal Xian Constr. Univ. Sci. Tech. 1996; 28:6-9. (In Chinese).

[37] Alonso C, Andrade C, Rodriguez J, Diez J.M., Factors controlling cracking of concrete affected by reinforcement corrosion, materials and structures. 1998, Vol 21, (211) pp435-441.

[38] Geocisa and Torroja Institute, Contecvet: A validated users manual for assessing the residual service life of concrete structures. Manuel for assessing corrosion-affected concrete structures. Annex C Calculation of a representative corrosion rate. EC Innovation Program IN309021. British Cement Association, UK, 2002.

[39] Ribas Silva M and Pinheiro S M M. Microbial Impact on concrete microstructure of world heritage in Brasilia. RILEM Proceeedings PRO-34 Microbial impact on Building materials. Madrid July, 2006.

[40] Luping T, Andersen A. Chloride ingress data from five years field exposed in a Swedish marine environment. In: 2nd International Workshop on Testing and Modelling the Chloride Ingress into Concrete, Paris 2000. p. 1-15.

[41] Melchers RE. Structural reliability-analysis and prediction. Chichester: Ellis Horwood Series in Civil Engineering; 1999. 
[42] Hong HP. Assessment of reliability of aging reinforced concrete structures. Journal of Structural Engineering, ASCE 2000; 126:1458-65.

[43] Thoft-Christensen P. Stochastic Modelling of the Crack Initiation Time for Reinforced Concrete Structures. In: ASCE 2000 Structures Congress, Philadelphia, USA 2000. p. 1-8.

[44] Kent DC, Park R. Flexural Members with Confined Concrete. Journal of the Structural Division, ASCE 1971; 97:1969-90.

[45] Stewart, M.G. and Val, D., Role of Load History in Reliability-Based Decision Analysis of Ageing Bridges. Journal of Structural Engineering ASCE, 1999; 125: 776-83. 


\section{List of Tables}

1. Cost of corrosion in several industrial and infrastructure sectors.

2. Effects of bacteria on RC structures.

3. Five species of Thiobacillus and their characteristics.

4. Biodeterioration rates caused by ASOM.

5. Probabilistic description of the variables used in the model.

\section{List of Figures}

1. Reliability profile for RC structures subject to corrosion.

2. Steel corrosion process combined with concrete cracking and biodeterioration effects.

3. Conceptual description of the coupled model for biodeterioration, chloride ingress and cracking of concrete structures.

4. (a) Change of the amount of corrosion products and the diameter of the steel bar with time; (b) Variation of the diffusion oxigen coefficient with time.

5. Time-dependent corrosion rates models.

6. Conceptual model or Biodeterioration.

7. (a) Age membership functions. (b) Biodeterioration rate membership functions.

8. (a) Surface generated in FIS type Mamdani. (b) Time-dependent biodeterioration rate function.

9. Flow diagram describing the coupled model.

10. Pile configuration. (a) description example, load and zones. (b) pile cross section.

11. Fragility curves for various average active biodeterioration rates. (a) $\theta=0.75$; (b) $\theta=0.5$; and (c) $\theta=0.25$.

12. Relationship between average active biodeterioration rate and structural lifetime for the three limit states considered. $\theta=0.75 ; \theta=0.5$; and $\theta=0.25$.

13. Variation of curvature ductility capacity with time. (a) $p_{f}=1$; (b) $p_{f}=0.5$. 
Table 1: Cost of corrosion in several industrial and infrastructure sectors Industrial sector Cost of corrosion 2001 (US\$Billion/year)

Gas \& Liquid Transmission pipelines

Hazardous Materials Storage

7.0

Highway bridges

7.0

Waterways \& ports

8.3

Drinking water and sewer systems

0.3

Transportation

36.0

Defense and nuclear waste storage

29.7

Production and manufacturing

20.1

Others

17.6

Total

11.9

137.9

Figure 1: Reliability profile for RC structures subject to corrosion.

Figure 2: Steel corrosion process combined with concrete cracking and biodeterioration effects. 
Table 2: Effects of bacteria on RC structures

\begin{tabular}{|c|c|c|c|}
\hline Bacteria type & Lifestyle & Temperatur & Consequences on concrete \\
\hline & & $\begin{array}{l}\text { and } \mathrm{pH} \\
\text { range }\end{array}$ & \\
\hline 1. Cyanobacteria & $\begin{array}{l}\text { Autothophic, } \\
\text { aerobe or } \\
\text { anaerobe }\end{array}$ & $\begin{array}{l}-60 \text { to } 85 \\
{ }^{\circ} \mathrm{C} \quad \text { (wide } \\
\text { range } p H \text { ) }\end{array}$ & $\begin{array}{l}\text { Generate tensile stresses leading } \\
\text { to an increment in the size of } \\
\text { cracks }\end{array}$ \\
\hline 2. Nitrobacteria & $\begin{array}{l}\text { Heterothophic } \\
\text { and anaer- } \\
\text { obe }\end{array}$ & $\begin{array}{l}18 \text { to } 25{ }^{\circ} \mathrm{C} \\
p H<7.5\end{array}$ & $\begin{array}{l}\text { Nitrates and nitrates attack the } \\
\text { concrete produce "calcium ni- } \\
\text { trate". this process affects the } \\
\text { concrete since it results from the } \\
\text { solubilisation of one of the ce- } \\
\text { ment components. }\end{array}$ \\
\hline $\begin{array}{l}3 . \quad \text { Sulfur-reducing } \\
\text { bacteria }\end{array}$ & $\begin{array}{l}\text { Heterothophic } \\
\text { and anaer- } \\
\text { obe }\end{array}$ & $\begin{array}{l}25 \text { to } 44{ }^{\circ} \mathrm{C} \\
5.5<p H< \\
9\end{array}$ & $\begin{array}{l}\text { Produce } \mathrm{H}_{2} \mathrm{~S} \text { that is used for the } \\
\text { Sulfur-oxidizing bacteria to pro- } \\
\text { duce sulfuric acid. This process is } \\
\text { commonly called Concrete Corro- } \\
\text { sion }\end{array}$ \\
\hline $\begin{array}{l}\text { 4. Sulfur-oxidizing } \\
\text { bacteria }\end{array}$ & $\begin{array}{l}\text { Heterothophic } \\
\text { and aerobe }\end{array}$ & $\begin{array}{l}25 \text { to } 44{ }^{\circ} \mathrm{C} \\
2<p H<9\end{array}$ & $\begin{array}{l}\text { Produce sulfuric acid, acetic acid, } \\
\text { sulfates, sulfur, sulfites and poly- } \\
\text { thionates that affect the concrete } \\
\text { chemically. }\end{array}$ \\
\hline $\begin{array}{lr}4.1 & \text { Neutrophilic } \\
\text { Sulfur } & \text { Oxidizing } \\
\text { (NSOM) } & \end{array}$ & & $p H \approx 7$ & \\
\hline $\begin{array}{lr}4.2 & \text { Acidophilic } \\
\text { Sulfur } & \text { Oxidizing } \\
\text { (ASOM) } & \end{array}$ & & $p H<3.0$ & \\
\hline
\end{tabular}

Table 3: Five species of Thiobacillus and their characteristics

\begin{tabular}{cccc}
\hline Species & pH range & Lifestyle & Products \\
\hline T. thioparus & $4.5-10$ & Autotrophic aerobe & Sulfur, Polythionic acids \\
T. novellus & $5-9.2$ & Mixotroph & Sulfur \\
T. neapolitanus & $4-9$ & Autotrophic & Polythionic acids, sulfuric acids \\
T. intermedius & $1.7-9$ & Mixotroph & Polythionic acids, sulfuric acids \\
T. thiooxidans & $0.5-4$ & Autotrophic & Sulfur, sulfuric acids \\
\hline
\end{tabular}

Table 4: Biodeterioration rates caused by ASOM

\begin{tabular}{cc}
\hline Source & Biodeterioration rate $(\mathrm{mm} / \mathrm{yr})$ \\
\hline Morton et al., 1991 [4] & 2.7 \\
Mori et al., 1992 [25] & $4.6-4.7$ \\
Ismail et al., 1993 [26] & $2-4$ \\
Davis, 1998 [27] & 3.1 \\
\hline
\end{tabular}


Table 5: Probabilistic description of the variables used in the model.

\begin{tabular}{ccccc}
\hline Variable & Distribution & Mean & Est. Dev. & Source \\
\hline Load & Lognormal & $400 \mathrm{kN}$ & $30 \mathrm{kN}$ & \\
$f^{{ }^{\prime}}{ }_{c}$ & Normal & $28 \mathrm{MPa}$ & $2.8 \mathrm{MPa}$ & Melchers, 1999 [41] \\
$f_{y}$ & Normal & $420 \mathrm{MPa}$ & $42 \mathrm{MPa}$ & Melchers, 1999 [41] \\
$C_{t h}$ & Lognormal & 0.37 & 0.04 & Hong, 2000 [42] \\
$C_{s}$ & Lognormal & 2 & 0.6 & Luping and Andersen, 2000 [40] \\
$D_{c l}$ & Lognormal & $1.62 \times 10^{-8} \mathrm{~cm}^{2} / \mathrm{s}$ & $0.5 \times 10^{-8} \mathrm{~cm}^{2} / \mathrm{s}$ & Hong, 2000 [42] \\
$\rho_{\text {rust }}$ & Normal & $3600 \mathrm{~kg} / \mathrm{m}^{3}$ & $360 \mathrm{~kg} / \mathrm{m}^{3}$ & Thoft-Christensen, 2000 [43] \\
$t_{\text {por }}$ & Lognormal & $12.5 \times 10^{-6} \mathrm{~m}$ & $2.54 \times 10^{-6} \mathrm{~m}$ & Thoft-Christensen, 2000 [43] \\
\hline
\end{tabular}

Figure 3: Conceptual description of the coupled model for biodeterioration, chloride ingress and cracking of concrete structures. 
Figure 4: (a) Change of the amount of corrosion products and the diameter of the steel bar with time; (b) Variation of the diffusion oxygen coefficient with time.

Figure 5: Time-dependent corrosion rates models. 
Figure 6: Conceptual model of Biodeterioration.

Figure 7: (a) Age membership functions. (b) Biodeterioration rate membership functions. 
Figure 8: (a) Surface generated in FIS type Mamdani. (b) Time-dependent biodeterioration rate function.

Figure 9: Flow diagram describing the coupled model. 
Figure 10: Pile configuration. (a) description example, load and zones. (b) pile cross section. 
Figure 11: Fragility curves for various average active biodeterioration rates. (a) $\theta=0.75$; (b) $\theta=0.5$; and (c) $\theta=0.25$.

Figure 12: Relationship between average active biodeterioration rate and structural lifetime for the three limit states considered. $\theta=0.75 ; \theta=0.5$; and $\theta=0.25$. 
Figure 13: Variation of curvature ductility capacity with time. (a) $p_{f}=1$; (b) $p_{f}=0.5$. 